\title{
Influence of Misalignment on Beveloid Gear Tooth Contact and Dynamic Characteristics in Transfer Case Transmission of AWD Vehicle
}

\author{
Bo Bai $(\mathbb{D}$, Yuhua Kuang, Wenchao Guo, and Shimin Mao \\ State Key Laboratory for Manufacturing Systems Engineering, Xi'an Jiaotong University, Xi'an 710054, China \\ Correspondence should be addressed to Shimin Mao; maosm@xjtu.edu.cn
}

Received 15 November 2021; Accepted 9 February 2022; Published 7 March 2022

Academic Editor: Emiliano Mucchi

Copyright ( 2022 Bo Bai et al. This is an open access article distributed under the Creative Commons Attribution License, which permits unrestricted use, distribution, and reproduction in any medium, provided the original work is properly cited.

\begin{abstract}
Beveloid gears are usually employed to transfer motion of small shaft angle, but the assembly errors or misalignment can affect the gear tooth contact and dynamic performance. A dynamic model and tooth contact analysis model of the intersecting beveloid gear pair are established, the defects of the theoretical tooth surface in the meshing are analyzed, and a microgeometry modification method to improve the meshing performance is proposed. At the same time, the effects of system misalignment and manufacturing errors on its meshing characteristics are considered. By studying the sensitivity of the static and dynamic characteristics of beveloid gear on different misalignment components, the influence laws of misalignment on the contact pattern, transmission error, mesh stiffness, and dynamic excitation force are obtained, which give suggestions for tooth surface modification and support structural stiffness design of beveloid gear with a good NVH performance.
\end{abstract}

\section{Introduction}

Beveloid gears are generalized involute gears in which tooth tip and root have a cone angle, tooth thickness is taper, and the tooth flank is involute helicoid. Each transverse section profile has the same base circle, but their profile shift coefficient along the axis has changed linearly. Many AWD vehicles' transfer cases usually have a beveloid gear pair with a small intersecting shaft angle, the driving pinion is a helical gear, the driven gear is a beveloid gear, and the tooth numbers are equal. The transmission schematic diagrams are shown in Figure 1. Transfer case with beveloid gear can avoid a structural obstacle and split the engine power into front axle power and final drive power. In addition, it has a smaller volume and light weight relative to a single or maybe twostage cylinder gear transfer case.

Merritt and Beam proposed the theory of beveloid gearing, respectively. In 1954, beveloid gear was applied widely until the general theory of the design, processing, and measurement of beveloid gear was elaborated by Mitome $[1,2]$ in 1983 . Beveloid gear pair, which has good backlash compensation characteristics, can be used to replace the cylindrical gear in precision parallel-axis transmission and can also be used in the intersecting or crossed shaft transmission with a small angle. Now beveloid gear is widely used in the transfer case of all-wheel-drive vehicles [3] and in the propulsion system of speedboats, as well as in marine transmission $[4,5]$.

Many studies on geometric design and machining methods for beveloid gears have been proceeding during the last decades. Liu and Tsay [6] investigated the condition of tooth toe undercutting and put forward two methods to avoid undercutting. Innocenti studied the hobbing kinematics parameters [7] and set up the theory of measurement over spheres of beveloid gears by simplifying its algebra [8]. Brecher [9] introduced a simulation-based method for function-oriented tolerancing of tooth flank modifications of beveloid gears.

In the aspect of tooth contact analysis (TCA) for beveloid gear pair, Mitome [10] analyzed the meshing characteristics of the theoretical tooth flank with an intersecting shaft, and the results show that it does not affect the accuracy of the 


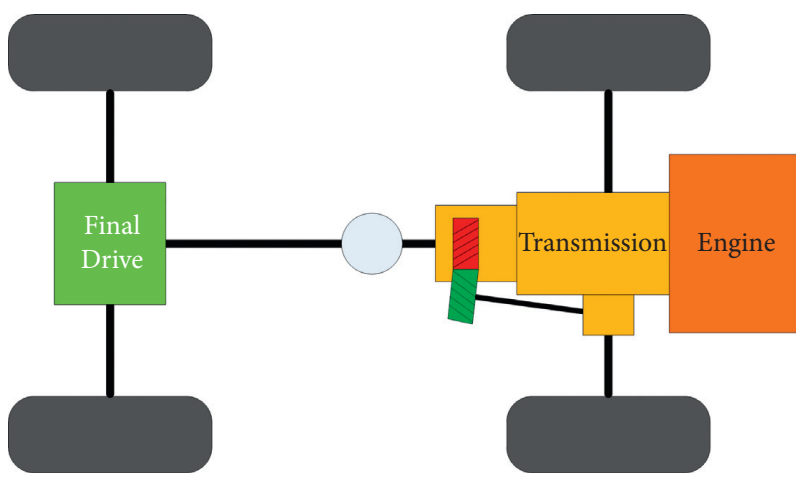

(a)

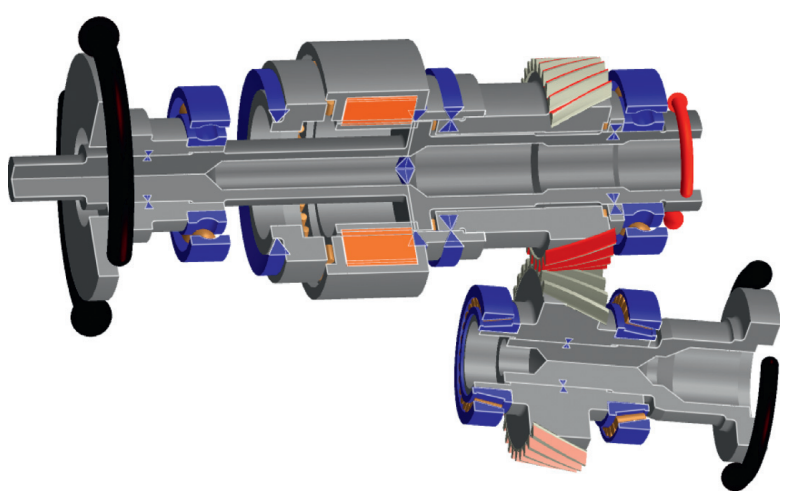

(b)

FIgure 1: Application and 3D models of small shaft angle beveloid gear. (a) Application in an AWD vehicle. (b) Transfer case.

transfer motion by point contact of the theoretical tooth surface with assembly errors. Meanwhile, Mitome studied the load capacity of beveloid gears based on Hertz theory. Innocenti [11] investigated the dependence of the backlash on the gear geometry and the shaft relative position. Liu and Tsay [12] analyzed the engaging characteristics of the theoretical tooth surface of nonparallel shaft beveloid gears by the TCA method and acquired the same conclusion as reference [10].

The theoretical tooth flank of beveloid gear is an involute helicoid, which is meshing as a point contact; with the increase of loading, the contact point will broaden into an ellipse, but the contact area is small, contact stress is large, and it is easily generated edge contact, which is very undesirable to the gear contact fatigue life. In order to improve these disadvantages, the modification tooth flanks usually are employed instead of the theoretical tooth flanks. Liu and Tsay [13] established a mathematical model of a concave tooth surface and conducted the tooth contact simulation; the tooth surface was a modification to a concave shape lengthwise relative to the theoretical tooth surface so that the instantaneous contact ellipse will be elongated and the contact area will be broader.

Brecher et al. took a simulation for grinding processing and tooth contact analysis of beveloid gears [14]; in addition, they investigated the influence relationships of machining method and motion performance [15]. Zhu and Song have a lot of valuable research on geometry design and tooth contact properties of marine crossed-axis beveloid gears [16-18]. Meanwhile, Song et al. analyzed the meshing characteristics and dynamic response of loaded beveloid gears with small shaft angle by parametric method [19, 20], and further on, they investigated the sliding friction effect on the gear dynamics and transmission error (TE) [21]. Trong Phu Do [22] established the elastic models for different types of beveloid gear and simulated contact force and TE in the process of tooth meshing. Until now, there are few works [23-25] on the static and dynamic mesh characteristics of beveloid gearing, which include structure deformation by load, assembly error, and tooth modifications; especially, there is a scarce study on the mesh properties of modification concave tooth surface under misalignment.
Although there has been a lot of research on the meshing characteristics of marine beveloid gears, the load condition of marine gears in water is not as complex as that of AWD off-road vehicles; because AWD off-road vehicles will bear particularly complex road conditions, especially under harsh conditions such as rapid acceleration, deceleration, and high-speed turning, the gear transmission torque will traverse the whole engine output torque range. In this case, in order to ensure the dynamic stability and reliability of the front and rear wheels of the vehicle, it is necessary to study the static and dynamic characteristics of the transfer case beveloid gear.

Consequently, this paper aims to study the contact characteristics of the modification concave beveloid gear used in the AWD vehicle transfer case with misalignment. The defects of its theoretical tooth surface in practical application will be discussed, a modification tooth surface that can improve the gear meshing performance will be presented, and then the error sensitivity on static meshing characteristics is going to be studied by loaded tooth contact analysis (LTCA, an FEM method) method. Meanwhile, the dynamic response characteristics of the beveloid gear pair under various misalignment errors will be analyzed. Finally, the influence laws of each component of misalignment errors on dynamic meshing performance of the gear system would be obtained.

\section{Beveloid Gear Pair Mesh Model and Mesh Characteristics}

2.1. Work Pitch Cone and Meshing Equation. Intersecting beveloid gear pair is usually employed to transfer power with a small shaft angle which is less than $20^{\circ}$; especially, if the shaft angle is less than $10^{\circ}$, one member in the gear pair will be designed as a cylinder gear. When the beveloid gear pair is meshing, the pitch cylinder of the helical gear and the pitch cone of the beveloid gear is tangent at the point $\mathrm{P}$, as shown in Figure 2. The origin of the global coordinate system $S_{g}\left(x_{g}, x_{g}, z_{g}\right)$ locates in the intersection point of gear shafts, and the origin of the local coordinate system $S_{1}\left(x_{1}, y_{1}, z_{1}\right)$ locates in the same position with $S_{g}\left(x_{g}, x_{g}, z_{g}\right)$, but $S_{2}\left(x_{2}, x_{2}, z_{2}\right)$ of beveloid gear locates in the pitch cone 


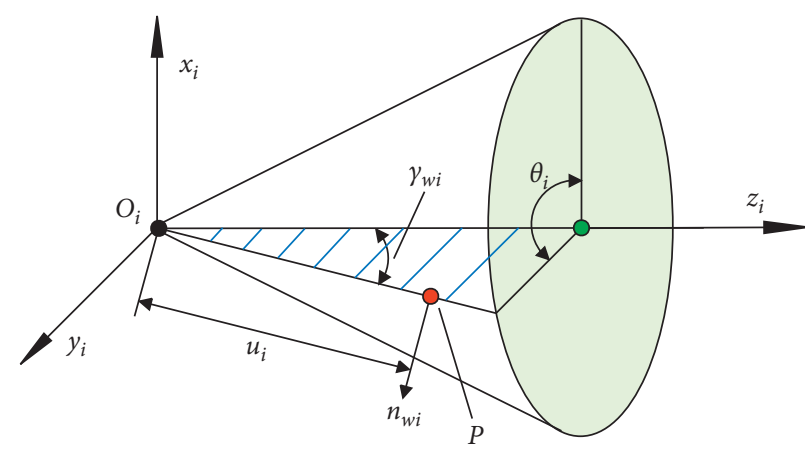

(a)

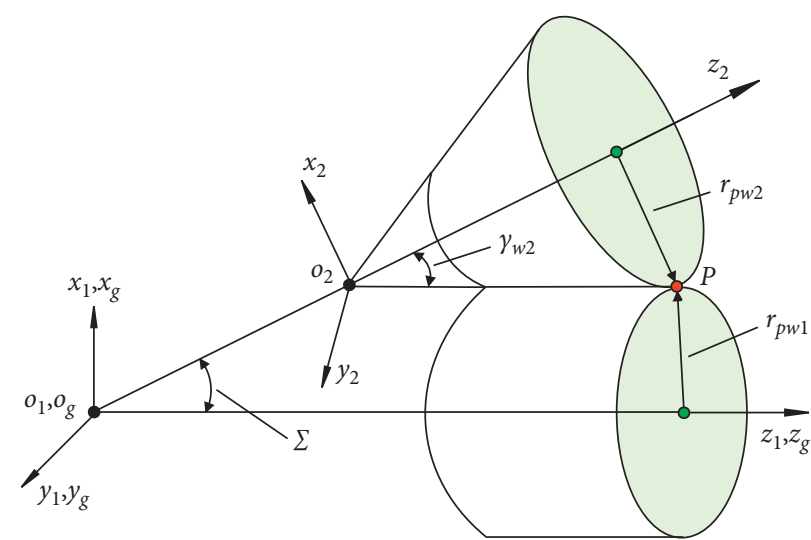

(b)

Figure 2: Beveloid gear work pitch cone model. (a) Work pitch cone. (b) Gear meshing coordinate system.

vertex, and the positive direction of axis $z$ is specified by the toe to the heel of gears. Here, the coordinate system $S_{g}\left(x_{g}, x_{g}, z_{g}\right)$ is fixed to the global frame, and the coordinate systems $S_{1}\left(x_{1}, x_{1}, z_{1}\right)$ and $S_{2}\left(x_{2}, x_{2}, z_{2}\right)$ are fixed to the pinion and gear, respectively.

$n_{w 1}$ and $\Delta X_{w} n$ denote the unit normal vector of point $\mathrm{P}$ on the generatrix of the pitch cone and cylinder, respectively. The position vector of point $\mathrm{P}$ can be expressed as

$$
r_{w i}=\left[\begin{array}{c}
x_{i} \\
y_{i} \\
z_{i}
\end{array}\right]=\left[\begin{array}{c}
u_{i} \sin \gamma_{w i} \cos \theta_{i} \\
u_{i} \sin \gamma_{w i} \sin \theta_{i} \\
u_{i} \cos \gamma_{w i}
\end{array}\right], \quad i=1,2 .
$$

The unit normal vector of point $\mathrm{P}$ can be calculated from

$$
n_{w i}=\frac{N_{i}}{\left|N_{i}\right|}=\frac{\partial r_{w i}}{\partial \theta_{i}} \times \frac{\partial r_{w i}}{\partial u_{i}} .
$$

Putting formula (1) to (2), then

$$
n_{w i}=\left[\begin{array}{c}
\cos \gamma_{w i} \cos \theta_{i} \\
\cos \gamma_{w i} \sin \theta_{i} \\
-\sin \gamma_{w i}
\end{array}\right] \text {. }
$$

To obtain the tangential equation of mating pitch cone surfaces, transform the position vector and unit normal vector of point $\mathrm{P}$ into the global coordinate system $S_{\mathrm{g}}$; the condition of tangency for mating pitch surfaces can be represented by

$$
\left\{\begin{array}{l}
r_{w 1}^{g}\left(u_{1}, \theta_{1}\right)=r_{w 2}^{g}\left(u_{2}, \theta_{2}\right) \\
n_{w 1}^{g}\left(u_{1}, \theta_{1}\right)=-n_{w 2}^{g}\left(u_{2}, \theta_{2}\right)
\end{array}\right.
$$

The formulas of coordinate system transformation are given by

$$
\begin{aligned}
r_{w i}^{g} & =\mathbf{M}_{w i}^{g} r_{w i} \\
n_{w i}^{g} & =\mathbf{M}_{w i}^{g} r_{w i}
\end{aligned}, \quad i=1,2,
$$

where $\mathbf{M}_{w i}^{g}$ is the matrix of coordinate transformation. According to the theory of engagement, the equation of meshing tooth surfaces is represented by

$$
\begin{aligned}
v^{(12)} \cdot n_{w 1}^{g} & =0, \\
v^{(12)} & =v_{1}-v_{2}=\omega_{1} \times r_{1}-\omega_{2} \times r_{2},
\end{aligned}
$$

where $v^{(12)}$ is the relative velocity vector of the pinion and gear contact point.

2.2. Transmission Error and Mesh Stiffness. The static transmission error (TE) is defined as the deviation of the ideal rotation angle and the actual rotation angle of the driven gear, but for the cylindrical gear pair, particularly, TE is always defined as a linear displacement in the line-ofaction direction which is transformed from an angular displacement

$$
T E=r_{b 2}\left(\phi_{2}^{\prime}-\phi_{1} / i\right)=\delta_{l}-\delta_{0}
$$

where $r_{\mathrm{b} 2}$ is the base radius of the driven gear, $\Phi_{1}$ and $\Phi_{2}$ denote the ideal rotation angle of driving and driven gear, respectively, $\phi_{2}^{\prime}$ means the actual rotation angle of the driven gear, $i$ is the transmission ratio, and $\delta_{l}$ and $\delta_{0}$ denote the loaded and unloaded transmission error in the line-of-action direction, respectively. When the gear tooth is meshing under load the instantaneous contact line can be divided into $N$ microsegments; it is assumed that each microsegment normal vector is $n_{i}\left(n_{i x}, n_{i y}, n_{i z}\right)$, and the normal force is $f_{i}$; as a consequence, the total contact force $F_{n}$ and its three components of instantaneous contact line can be calculated by

$$
\begin{aligned}
& F_{x}=\sum_{j=1}^{N} n_{j x} f_{j} \\
& F_{y}=\sum_{j=1}^{N} n_{j y} f_{j} \\
& F_{z}=\sum_{j=1}^{N} n_{j z} f_{j}, \\
& F_{n}=\sqrt{F_{x}^{2}+F_{y}^{2}+F_{y}^{2}},
\end{aligned}
$$


and then the actual mesh stiffness is expressed as

$$
\begin{aligned}
K & =F_{\text {total }} l\left[b \cdot\left(\delta_{l}-\delta_{0}\right)\right], \\
F_{\text {total }} & =\sum_{i=1}^{M} F_{n i},
\end{aligned}
$$

where $F_{\text {total }}$ is the total contact force of multiteeth meshing transiently, $b$ is the face width, and $M$ is the number of transient meshing tooth pairs.

By means of the loaded tooth contact analysis (LTCA) method, the distributed contact force and TE can be obtained; furthermore, the total contact force and mesh stiffness also can be calculated by equations (9)-(12).

2.3. Internal Dynamic Excitation of Meshing Gear Pair. In order to study the influence of time-varying mesh stiffness and transmission error on the dynamic mesh performance of the beveloid gear pair, a single-degree-of-freedom discrete rotor system of the beveloid gear is established as shown in Figure 3. The model consists of a pair of intersecting shaft gear pair, power input and output unit, and bearing support unit, drive and driven gear are modeled rigid bodies, and the meshing pair is modeled as a set of damping, stiffness, and error elements.

The equations of gear motion can be represented by

$$
\begin{gathered}
J_{1} \ddot{\theta}_{1}+r_{b 1} c_{m}\left(r_{b 1} \dot{\theta}_{1}-r_{b 2} \dot{\theta}_{2}\right)-\left(r_{b 1} c_{1} \dot{e}_{1}+r_{b 1} c_{2} \dot{e}_{2}\right)+r_{b 1} k_{m} \\
\left(r_{b 1} \theta_{1}-r_{b 2} \theta_{2}\right)-\left(r_{b 1} k_{1} e_{1}+r_{b 1} k_{2} e_{2}\right)=T_{1}, \\
J_{2} \ddot{\theta}_{2}+r_{b 2} c_{m}\left(r_{b 2} \dot{\theta}_{2}-r_{b 1} \dot{\theta}_{1}\right)+\left(r_{b 2} c_{1} \dot{e}_{1}+r_{b 2} c_{2} \dot{e}_{2}\right)+r_{b 2} k_{m} \\
\left(r_{b 2} \theta_{2}-r_{b 1} \theta_{1}\right)+\left(r_{b 2} k_{1} e_{1}+r_{b 2} k_{2} e_{2}\right)=-T_{2} .
\end{gathered}
$$

where $k_{\mathrm{i}}, c_{\mathrm{i}}$, and $e_{\mathrm{i}}, i=1,2$, denote the mesh stiffness, mesh damping, and error of the $i$-th tooth pair, respectively, and $c_{\mathrm{m}}$ and $k_{\mathrm{m}}$ indicate the combined mesh damping and mesh stiffness, respectively. It is assumed that the relative displacement of gear along line-of-action, namely, the dynamic transmission error (DTE) $x$, is expressed as

$$
x=r_{b 1} \theta_{1}-r_{b 2} \theta_{2},
$$

and the excitation force $F$ is expressed as

$$
F=m_{\mathrm{e}} \ddot{x}+c_{m} \dot{x}+k_{m} x=F_{0}+c_{1} \dot{e}_{1}+c_{2} \dot{e}_{2}+k_{1} e_{1}+k_{2} e_{2},
$$

where $m_{\mathrm{e}}$ denotes the equivalent mass and $F_{0}$ indicates the static circumferential force:

$$
\begin{aligned}
& m_{\mathrm{e}}=\frac{m_{1} m_{2}}{m_{1}+m_{2}}=\frac{J_{1} J_{2}}{J_{1} r_{b 2}^{2}+J_{2} r_{b 1}^{2}}, \\
& F_{0}=T_{1} / r_{b 1}=T_{2} / r_{b 2},
\end{aligned}
$$

and the dynamic contact force $F_{\mathrm{d}}$ can be represented by

$$
F_{d}=c_{m} \dot{x}-c_{1} \dot{e}_{1}-c_{2} \dot{e}_{2}+k_{m} x-k_{1} e_{1}-k_{2} e_{2},
$$

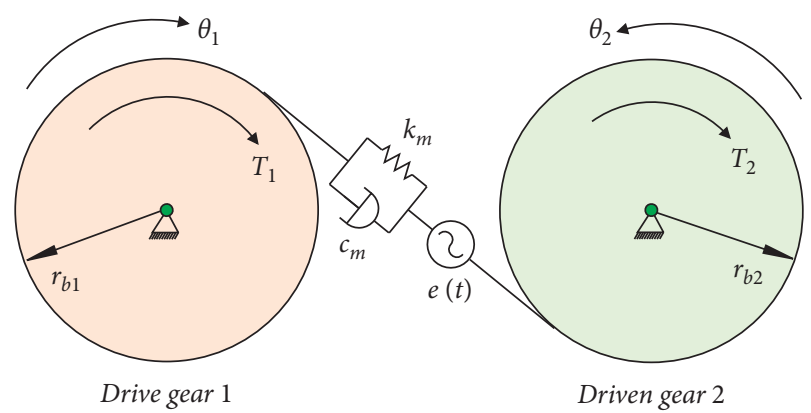

FIguRe 3: Dynamic model of meshing gear pair.

therefore, the DTE $x$ can also be expressed as

$$
x=F_{d} / k_{m}+\frac{c_{1} \dot{e}_{1}+c_{2} \dot{e}_{2}}{k_{m}}+\frac{k_{1} e_{1}+k_{2} e_{2}}{k_{m}}-c_{m} \dot{x} / k_{m} .
$$

The discrete steady-state response of the linear timeinvariant model can be solved in the frequency domain, and the dynamic transmission error and dynamic mesh force can be obtained from equations (16) and (17), respectively.

2.4. Misalignment Conventions for Beveloid Gear Set. The misalignment of nonparallel shaft gear pair can reference hypoid gears' definition. As shown in Figure $4, \Delta \Sigma$ represents the shaft angle $\Sigma$ deviation from the theoretical position; if $\Delta \Sigma$ is positive, this means the shaft angle $\Sigma$ increases; $\Delta E$ indicates the offset distance $E$ deviation from the theoretical position; if $\Delta E$ is positive, this means the offset distance increases; when the design offset is zero, the positive $\Delta E$ indicates the pinion deviation along the $y$ direction. Gear mounting distance deviations $\left(\Delta X_{p}\right.$ and $\left.\Delta X_{w}\right)$ represent the mounting position error in the axial direction and specify the positive deviation toward the heel end $(+z$ direction).

\section{Loaded Tooth Contact Analysis and Tooth Surface Modification under Service Condition}

3.1. Beveloid Gear Pair Geometry Parameters in a Transfer Case. A pair of beveloid gears are designed for an AWD vehicle transfer case, and the basic geometry parameters are shown in Table 1.

Take these gear pair parameters in Table 1 into equations (1)-(7); the point set of tooth surfaces which is shown in Figure 5(a) can be solved; furthermore, the 3D geometry model of the beveloid gear pair can be built as shown in Figure 5(b).

3.2. The Necessity of Tooth Surface Modification. Beveloid and helical gears' theoretical tooth surfaces are both spiral involute surfaces, and their transient tooth contact pattern is a point without load, although the contact point will expand into a line when the teeth are loaded, but the contact area maintains narrow still, and the contact stress is high and 


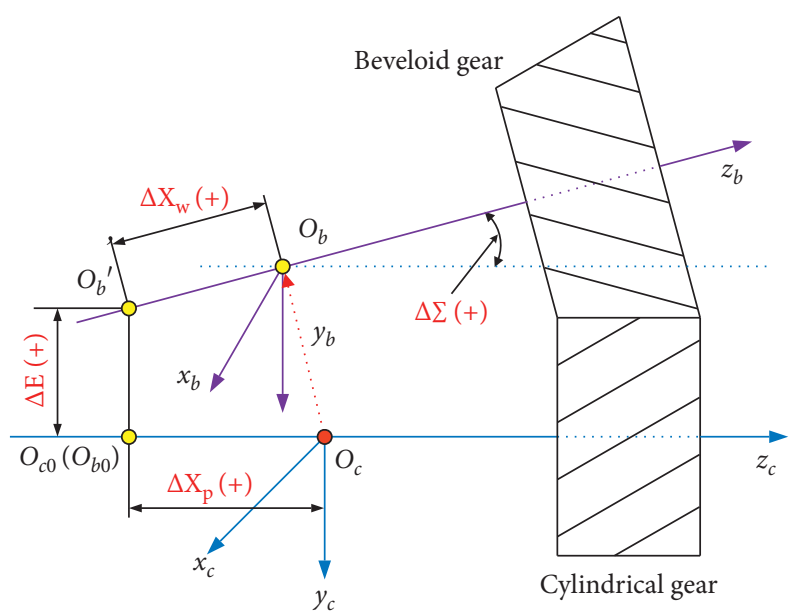

FIGURE 4: Misalignment conventions of beveloid gear pair.

TABLE 1: The main parameters of beveloid gear pair.

\begin{tabular}{|c|c|c|c|}
\hline & Symbol & Pinion (helical gear) & Wheel (beveloid gear) \\
\hline Number of teeth & $z$ & 33 & 33 \\
\hline Normal module $(\mathrm{mm})$ & $m_{n}$ & & 2.5754 \\
\hline Normal pressure angle (deg) & $\alpha_{n}$ & & 20 \\
\hline Helix angle (deg) & $\beta$ & $30(\mathrm{LH})$ & 31.72 (left flank); 27.93 (right flank) \\
\hline Toe addendum modification coefficient & $x_{t}^{*}$ & 0 & -0.53 \\
\hline Heel addendum modification coefficient & $x_{h}^{*}$ & 0 & 0.53 \\
\hline Face width $(\mathrm{mm})$ & $b$ & 32 & 30 \\
\hline Pitch cone angle (deg) & $\delta$ & 0 & 6 \\
\hline Shaft angle (deg) & $\Sigma$ & & 6 \\
\hline
\end{tabular}

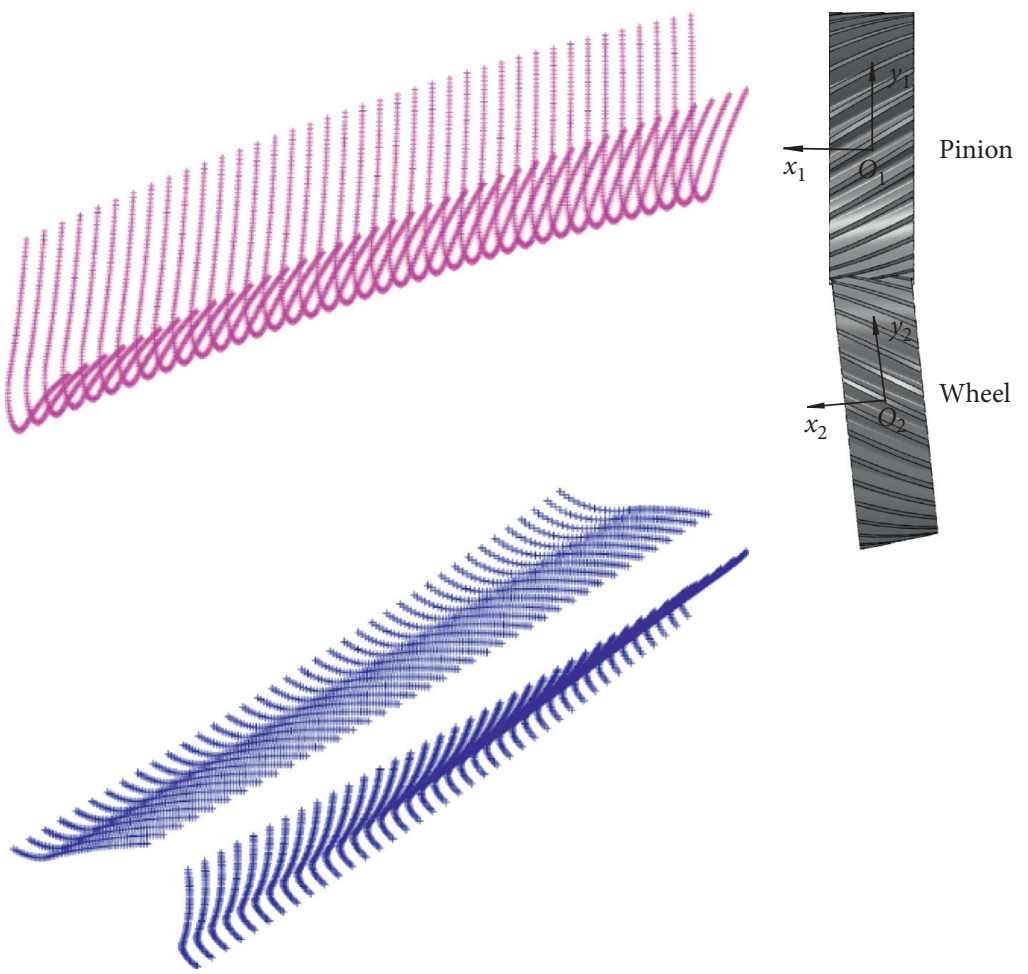

(a)

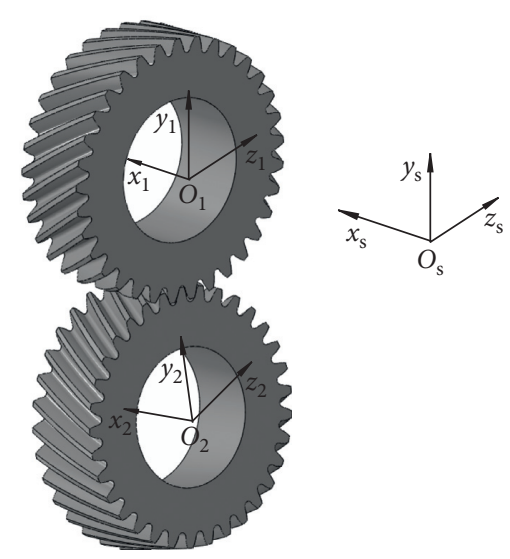

(b)

FIgURE 5: Geometry model of shaft intersecting beveloid gear pair. (a) Points set of tooth surfaces. (b) Beveloid gear pair 3D model. 
prone to generate edge contact, which is very unfavorable to fatigue life.

Gear meshing performance has a great relationship with misalignment, which contains system deformation and assembly errors in working. The misalignment usually affects static and dynamic meshing performance, such as premature fatigue failure, scuffing, wear, vibration, and noise (Figure 6).

The beveloid gear pair in this example has a misalignment of $\triangle \Sigma=0.313 \mathrm{mrad}, \quad \triangle E=-0.06 \mathrm{~mm}$, $\triangle \mathrm{Xp}=0.162 \mathrm{~mm}$, and $\triangle \mathrm{Xw}=-0.19 \mathrm{~mm}$ under $200 \mathrm{Nm}$ input torque; the results of loaded tooth contact analysis (LTCA) of the theoretical tooth surface are shown in Figure $7(\mathrm{a})$; there is a serious edge contact on the tooth tip and root; edge contact can induce vibration and impact when the tooth enter or exit meshing and could lead gears to early failure such as pitting or scuffing if edge contact stress value is greater than the allowance value.

To improve the undesirable contact pattern, the edge contact, and vibration problem under misalignment, the modification tooth surface must be used to replace the theoretical one tooth surface. A concave parabolic end relief for beveloid gear was designed in the longitudinal direction relative to the theoretical tooth surface; that is, we took the theoretical tooth surface as the baseline; a parabolic end antirelief was used in the tooth toe and heel end; consequently, the instantaneous contact line will be lengthened, and the contact area will be extended. Tip and root relief, maybe plus involute barrelling, can resolve the edge contact problem, but the tip and root relief are difficult for the beveloid gear; therefore, the involute modification is implemented on the mating helical gear.

In the following, the work to optimize the contact pattern and reduce the contact stress and peak-to-peak transmission error (PPTE) by tooth surface microgeometry modification has been carried out. The optimized helical gear microgeometry modifications are shown in Table 2, and the microgeometry modifications of the beveloid gear are shown in Table 3. The modification topographies of the tooth surface are shown in Figure 6.

\subsection{Results of Loaded Tooth Contact Analysis}

3.3.1. The Improvement of Contact Pattern. After tooth surface micromodification, according to the data of Table 2 and Table 3, the contact stress of the tooth surface has been calculated by LTCA. Figure 7 shows the comparison of tooth surface contact patterns before and after optimization; there are indeed improvements after modification, the maximum contact stress is located in the center of the tooth surface, edge contact does not occur at the tooth tip and root anymore, the contact area is wider, and the load distribution is more reasonable.

3.3.2. The Improvement of Contact Stress. The contact stress curves of the tooth flank by quasistatic calculation are shown in Figure 8; we can find that the contact stress of the optimized tooth flank is generally smaller than the original flank; meanwhile, the maximum stress of the original flank is
1116.4 MPa, but after the optimized maximum stress declined to $736.2 \mathrm{MPa}$, the maximum value significantly reduced $34 \%$, and the fluctuation degree of stress changed from drastic to stable.

3.3.3. The Improvement of Transmission Error. In the design objective of the automobile transfer case, the peak-to-peak transmission error (PPTE) should be less than $0.5 \mu \mathrm{m}$ at least in the NVH testing conditions; in order to satisfy a low noise and vibration for the gear transmission system, it is well known that PPTE is a significant internal excitation. The TE curves calculated by quasistatic LTCA are shown in Figure 9; after tooth modification, the PPTE reduced from $0.51 \mu \mathrm{m}$ to $0.39 \mu \mathrm{m}$, and the harmonics of TE after fast Fourier transform had also reduced.

\section{Error Sensitivity Analysis of Beveloid Gear Meshing Characteristics under Misalignment}

As we all know, the torque of a vehicle is constantly changing during driving, and the gear pair misalignment is changed with torque; therefore, whether a matched tooth surface optimization parameters can adapt to a variety of load conditions and whether it has a satisfactory meshing performance, practices have proved that this is a great challenge. Otherwise, if we can let the gear pair works in a well-supported environment so that the misalignment is in a reasonable range under the working load spectrum, then a set of optimized tooth surface parameters can be well adapted to different working conditions. Consequently, we should first study the sensitivity of gear meshing performance under different misalignment and then reduce the misalignment in the highly sensitive direction during structural design and assembly so that the gear system can acquire a good performance. Therefore, three types of misalignment of the modification beveloid gear pairs were studied separately, and their effects on the static and dynamic transmission performance were analyzed.

\subsection{Error Sensitivity Analysis of Static Meshing Characteristics}

4.1.1. Contact Patterns. The contact patterns under diverse shaft angle deviation $\Delta \Sigma$ are shown in Figure 10 (top). When $\Delta \Sigma$ is positive, the contact pattern tends to move to the toe end; otherwise, when $\Delta \Sigma$ is negative, the contact pattern will move to the heel end; if the absolute value of $\Delta \Sigma$ is large enough, the stress concentration will appear on the heel or toe edge of the tooth, and the contact area will be smaller as long as there exists an error of shaft angle. Consequently, the contact area is influenced significantly by the shaft angle deviation.

The contact patterns under various offset deviations $\Delta E$ are shown in Figure 10 (middle). The effect of $\Delta E$ on tooth contact pattern is similar to the $\Delta \Sigma$; likewise, if the absolute value of $\Delta E$ is large enough, the stress concentration will appear on the heel or toe end.

The contact patterns under different mounting distance deviation $\Delta X$ are shown in Figure 10 (bottom). As a rule, 

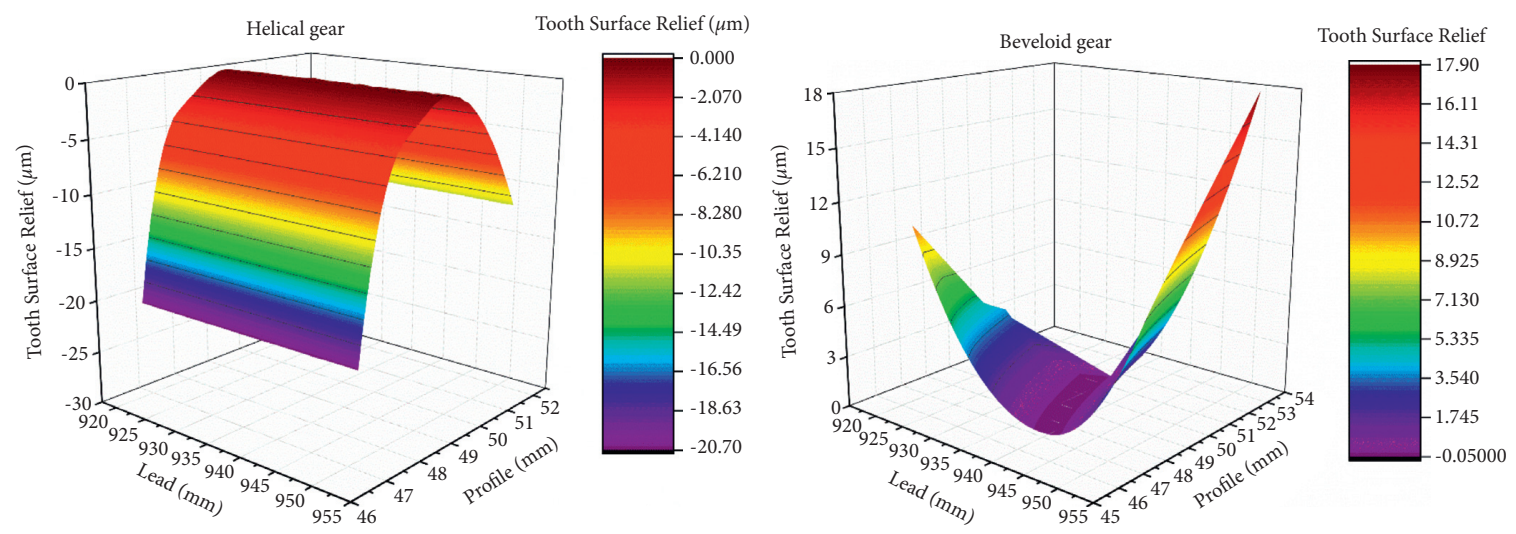

FIGURE 6: Topographies of tooth surface modification.
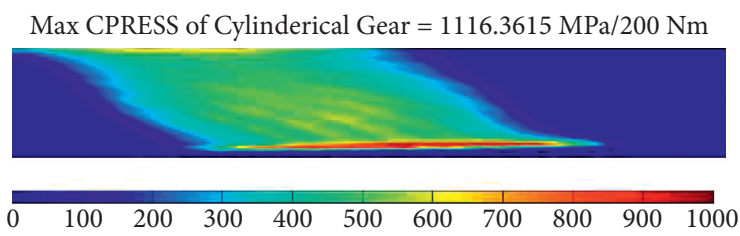

Max CPRESS of Beveloid Gear $=1040.3801 \mathrm{MPa} / 200 \mathrm{Nm}$

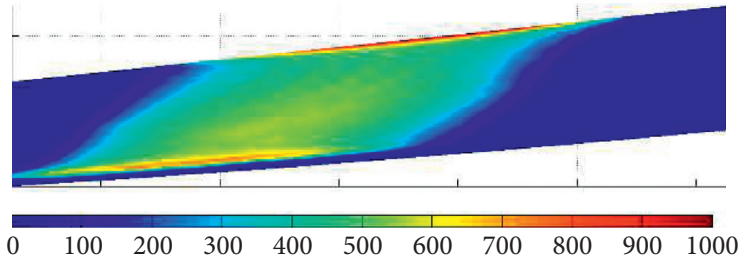

(a)
Max CPRESS of Cylinderical Gear $=703.9256 \mathrm{MPa} / 200 \mathrm{Nm}$
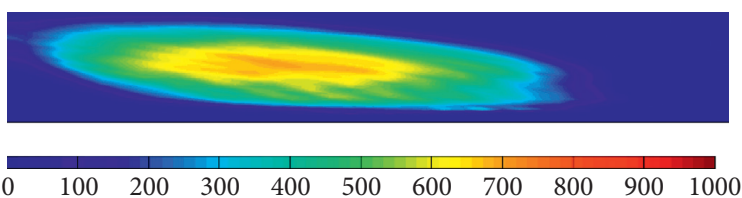

Max CPRESS of Beveloid Gear $=736.2138 \mathrm{MPa} / 200 \mathrm{Nm}$

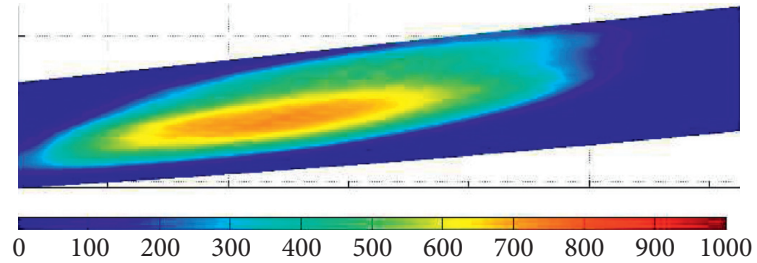

(b)

FiguRE 7: LTCA of theory and modification tooth surface under misalignment $(\triangle \Sigma=0.313 \mathrm{mrad}, \triangle E=-0.06 \mathrm{~mm}, \triangle \mathrm{Xp}=0.162 \mathrm{~mm}$, and $\triangle \mathrm{Xw}=-0.19 \mathrm{~mm}$ ) in the work environment. (a) Theory design. (b) Modification design.

TABLE 2: Micromodification parameters of helical gear.

\begin{tabular}{|c|c|c|c|c|}
\hline & Item & Symbol & Right flank (drive side) & Left flank (coast side) \\
\hline \multirow{8}{*}{ Tooth profile } & Start point (tif) (rad) & $u_{S T}$ & 0.1780 & 0.1780 \\
\hline & End point (eap) (rad) & $u_{E N D}$ & 0.5628 & 0.5628 \\
\hline & Barrelling $(\mu \mathrm{m})$ & $\delta_{P C}$ & 0 & 0 \\
\hline & Slope $(\mu \mathrm{m})$ & $\delta_{P A}$ & -17 & -17 \\
\hline & Tip relief start (rad) & $u_{T}$ & 0.4 & 0.4 \\
\hline & Tip parabolic relief $(\mu \mathrm{m})$ & $\delta_{P T}$ & 20 & 20 \\
\hline & Root relief start (rad) & $u_{R}$ & 0.35 & 0.35 \\
\hline & Root parabolic relief $(\mu \mathrm{m})$ & $\delta_{P R}$ & 25 & 25 \\
\hline
\end{tabular}

TABle 3: Micromodification parameters of beveloid gear.

\begin{tabular}{ccccc}
\hline & Item & Symbol & Right flank (drive side) & Left flank (coast side) \\
\hline & Heel end relief length $(\mathrm{mm})$ & $L_{H}$ & 15 & 15 \\
\multirow{4}{*}{ Tooth lead } & $\delta_{H 2 P}$ & 20 & 20 \\
& Heel quadratic parabolic end relief $(\mu \mathrm{m})$ & $\delta_{H 4 P}$ & -10 & -10 \\
& Heel quartic parabolic end relief $(\mu \mathrm{m})$ & $L_{T}$ & 15 & 15 \\
Toe end relief length $(\mathrm{mm})$ & $\delta_{T 2 P}$ & -10 & 15 \\
& Toe quadratic parabolic end relief $(\mu \mathrm{m})$ & $\delta_{T 4 P}$ & -10 \\
\hline
\end{tabular}




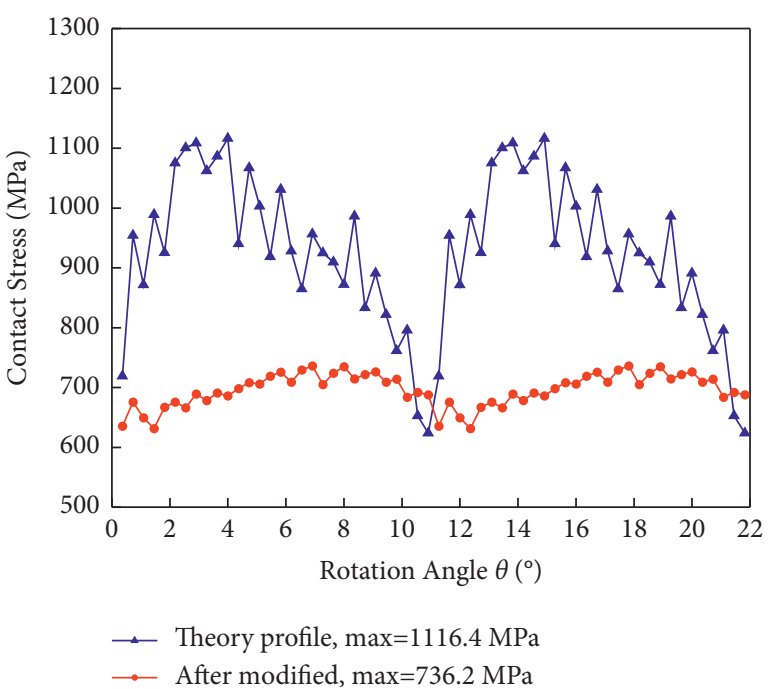

(a)

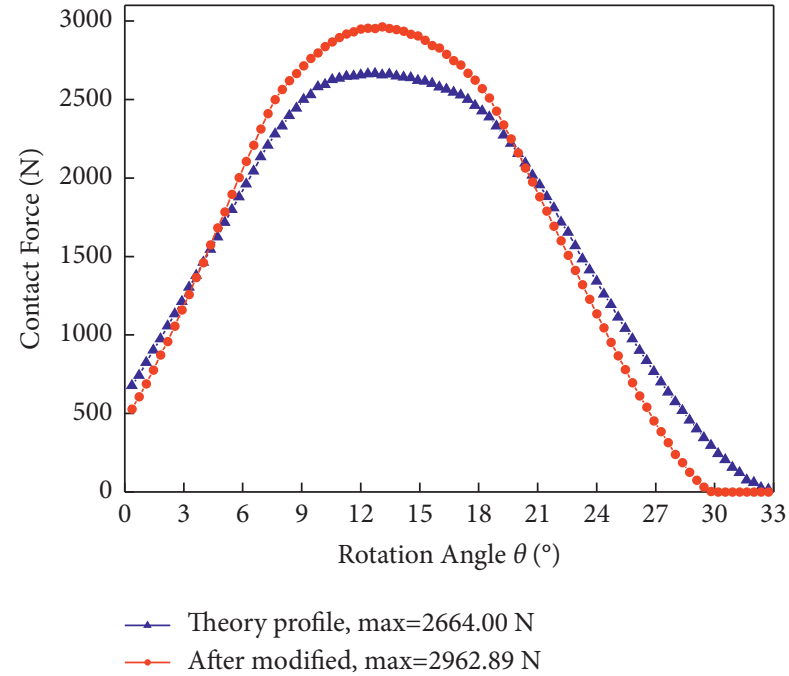

(b)

Figure 8: Contact stress and contact force for a single tooth. (a) Contact stress. (b) Contact force.

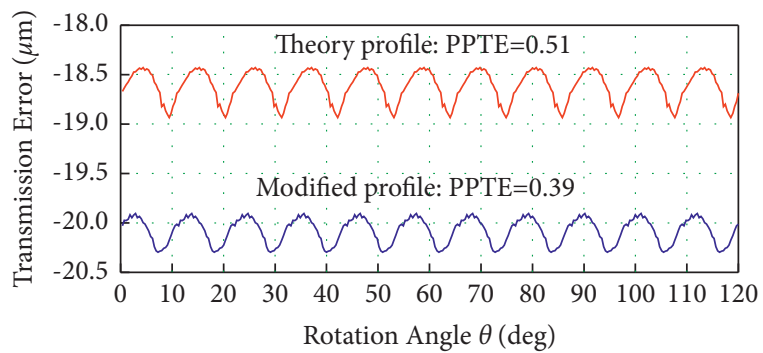

(a)

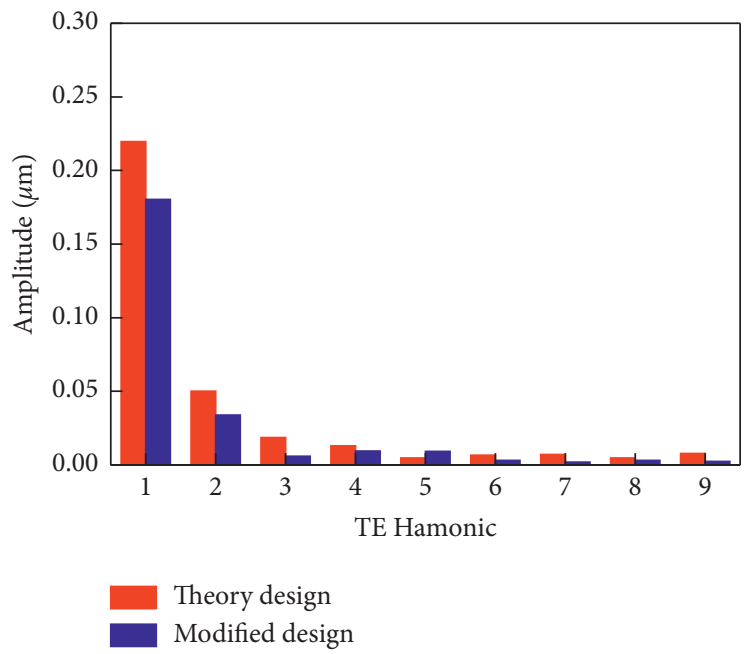

(b)

FiguRE 9: Transmission error of theory and modification design.

cylindrical gears are insensitive to axial direction displacement; the cylindrical gear has neither a positive $\Delta X_{p}$ nor a negative $\Delta X_{p}$; the contact pattern will hardly change, but the contact pattern of the beveloid gear has an obvious change if $\Delta X_{w}$ is not zero; when $\Delta X_{w}$ is positive, the contact pattern moves to the toe end slightly; in contrast, the contact pattern moves to the heel end slightly when $\Delta X_{w}$ is negative. Furthermore, we can use $\Delta X_{w}$ of the beveloid gear to adjust the backlash of the gear pair and to modify the transmission accuracy.

4.1.2. Transmission Error. The TE curves under various misalignments are shown in Figure 11. It can be seen that the $\Delta \Sigma$ has a few influences on the TE; the negative $\Delta \Sigma$ makes the average TE and PPTE decline, but the positive $\Delta \Sigma$ changes the average TE and PPTE indistinctively. $\Delta E$ can reduce the average TE, but it will increase the PPTE value. $\Delta X_{p}$ has a hard influence on the TE but $\Delta X_{w}$ is similar to $\Delta E$, which has a signal influence on TE and PPTE.

4.1.3. Time-Varying Mesh Stiffness. Figure 12 shows the time-varying mesh stiffness curve of the gear set under diverse misalignment; it can be seen that the shaft angle deviation $\Delta \Sigma$ has slight effects on the mesh stiffness; specifically, the negative $\Delta \Sigma$ strengthens the average mesh stiffness, and the positive $\Delta \Sigma$ changes the average mesh stiffness indistinctively; with the increase of $\Delta \Sigma$, the mesh stiffness peak-to-peak value first increases and then decreases. The offset distance deviation $\Delta E$ will increase the mesh stiffness clearly; both positive and negative $\Delta E$ will 


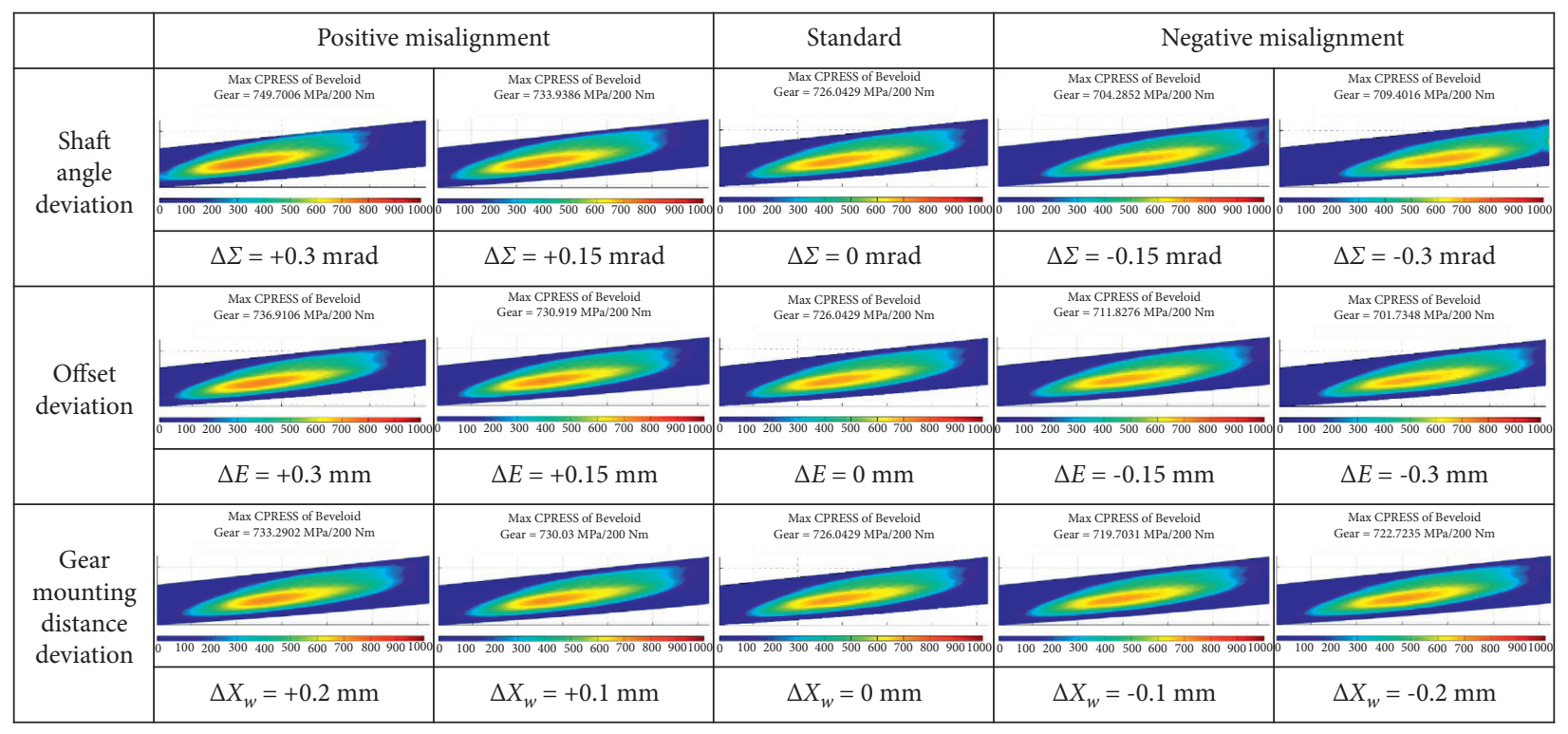

FIGURE 10: Contact patterns of beveloid gear under intentional misalignment.
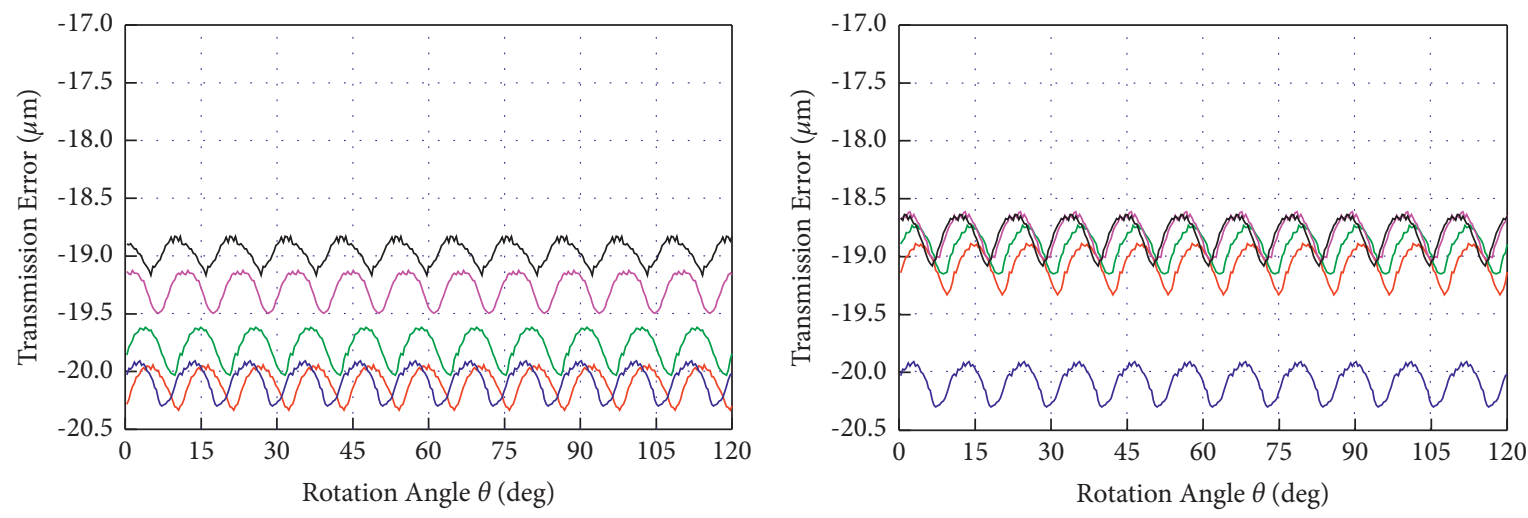

$-\Delta \sum=0.3 \mathrm{mrad}, \mathrm{PPTE}=0.39$

$-\Delta \mathrm{E}=0.3 \mathrm{~mm}, \mathrm{PPTE}=0.44$

- $\Delta \Sigma=0.15 \mathrm{mrad}, \mathrm{PPTE}=0.41$

$\Delta \mathrm{E}=0.15 \mathrm{~mm}, \mathrm{PPTE}=0.42$

$\Delta \Sigma=0$, PPTE $=0.39$

$-\Delta \Sigma=-0.15 \mathrm{mrad}, \mathrm{PPTE}=0.37$

$-\Delta \mathrm{E}=0, \mathrm{PPTE}=0.39$

- $\Delta \Sigma=-0.3 \mathrm{mrad}, \mathrm{PPTE}=0.34$

$-\Delta \mathrm{E}=-0.15 \mathrm{~mm}, \mathrm{PPTE}=0.42$

$-\Delta \mathrm{E}=-0.3 \mathrm{~mm}, \mathrm{PPTE}=0.45$

(a)

(b)

FIGURE 11: Continued. 

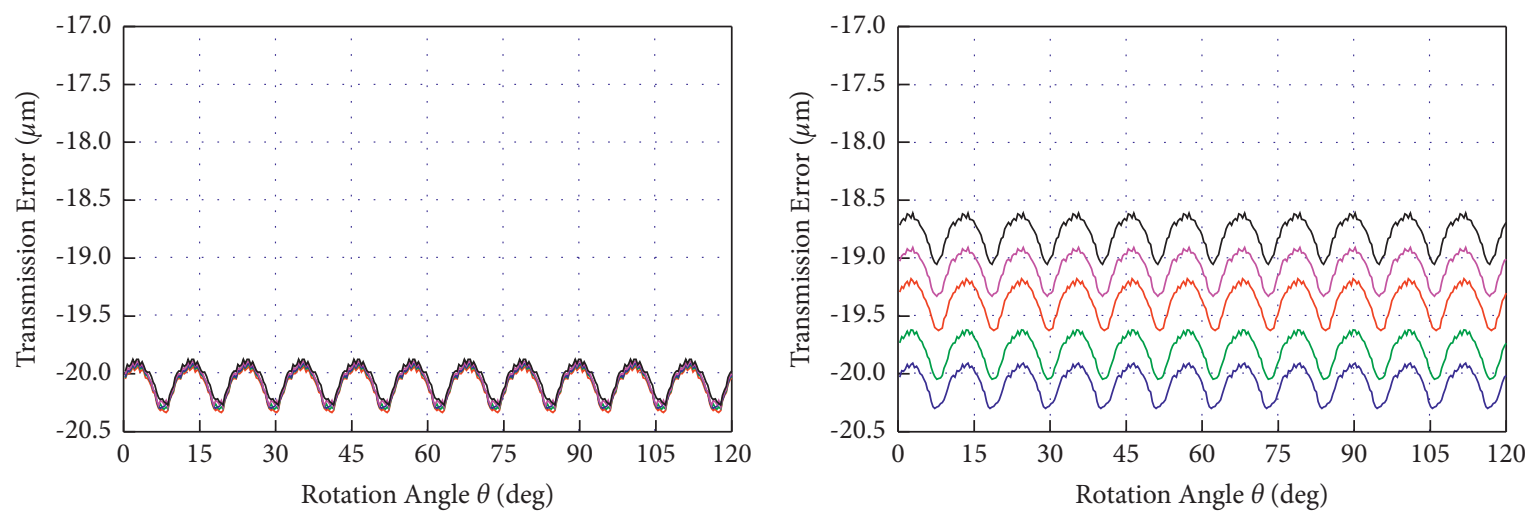

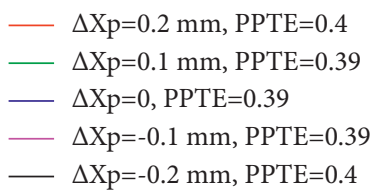

(c)

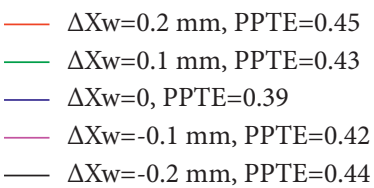

(d)

Figure 11: Time-varying transmission error. (a) Shaft angle deviation. (b) Offset deviation. (c) Pinion mounting distance deviation. (d) Wheel mounting distance deviation.
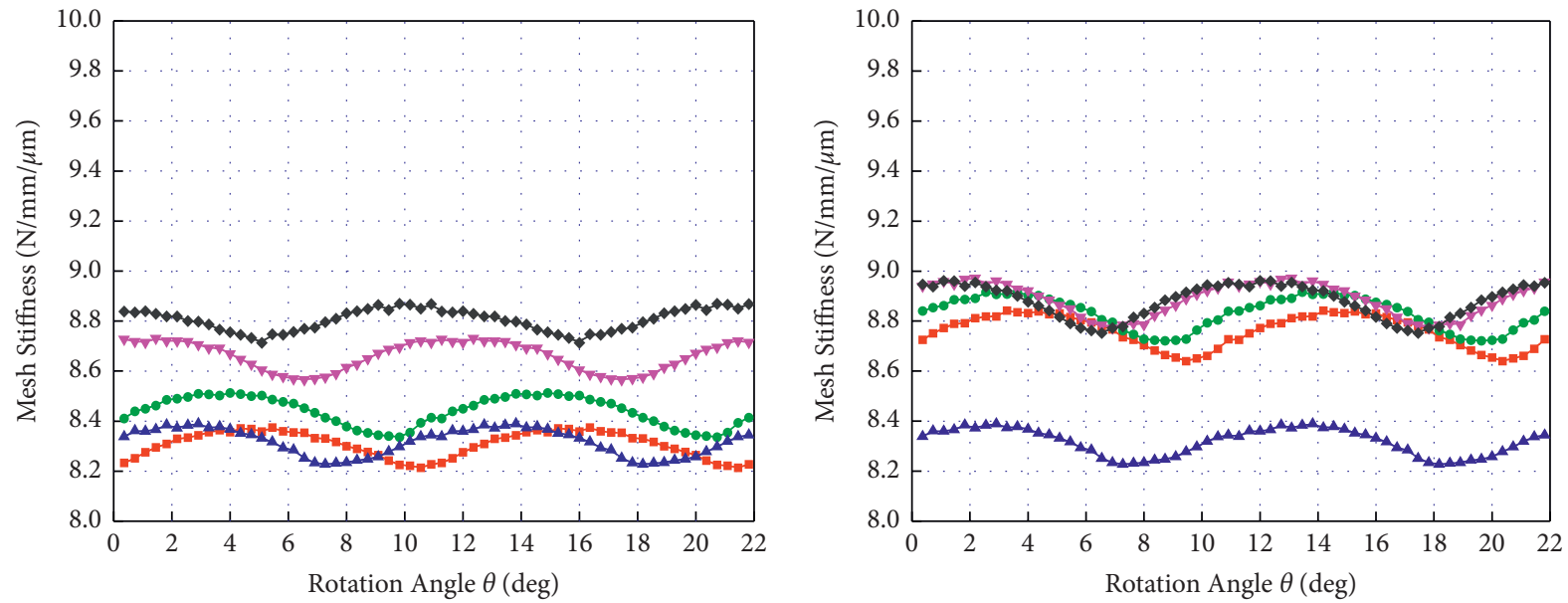

- $\Delta \sum=0.3 \mathrm{mrad}$, peak-peak value $=0.161$

- $\Delta \mathrm{E}=0.3 \mathrm{~mm}$, peak-peak value $=0.202$

- $\Delta \sum=0.15 \mathrm{mrad}$, peak-peak value $=0.176$

$\rightarrow \Delta \sum=0$, peak-peak value $=0.162$

$\rightarrow \Delta \sum=-0.15 \mathrm{mrad}$, peak-peak value $=0.166$

$\rightarrow \Delta \Sigma=-0.3 \mathrm{mrad}$, peak-peak value $=0.157$

$\rightarrow \Delta \mathrm{E}=0.15 \mathrm{~mm}$, peak-peak value $=0.195$

$\leadsto \Delta \mathrm{E}=0$, peak-peak value $=0.162$

$\rightarrow \Delta \mathrm{E}=-0.15 \mathrm{~mm}$, peak-peak value $=0.199$

$\rightarrow \Delta \mathrm{E}=-0.3 \mathrm{~mm}$, peak-peak value $=0.209$

(a)

(b)

Figure 12: Continued. 

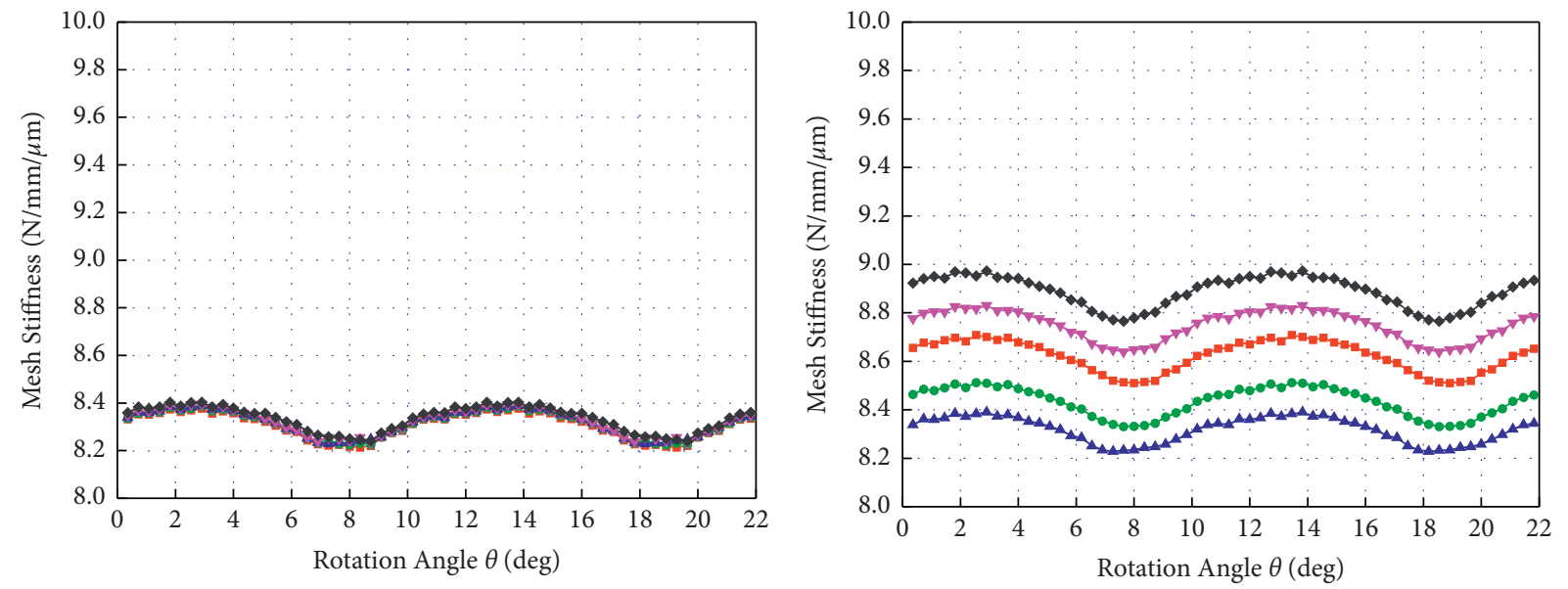

$-\Delta \mathrm{Xp}=0.2 \mathrm{~mm}$, peak-peak value $=0.163$

- $\Delta \mathrm{Xw}=0.2 \mathrm{~mm}$, peak-peak value $=0.198$

$\rightarrow \Delta \mathrm{Xp}=0.1 \mathrm{~mm}$, peak-peak value $=0.163$

$\rightarrow \Delta \mathrm{Xw}=0.1 \mathrm{~mm}$, peak-peak value $=0.181$

$\neg \Delta \mathrm{Xp}=0$, peak-peak value $=0.162$

$\rightarrow \Delta \mathrm{Xp}=-0.1 \mathrm{~mm}$, peak-peak value $=0.163$

$\rightarrow \Delta \mathrm{Xp}=-0.2 \mathrm{~mm}$, peak-peak value $=0.164$

$\neg \Delta \mathrm{Xw}=0$, peak-peak value $=0.162$

$\rightarrow \Delta \mathrm{Xw}=-0.1 \mathrm{~mm}$, peak-peak value $=0.192$

$\rightarrow \Delta \mathrm{Xw}=-0.2 \mathrm{~mm}$, peak-peak value $=0.207$

(c)

(d)

FIgure 12: Time-varying mesh stiffness. (a) Shaft angle deviation. (b) Offset deviation. (c) Pinion mounting distance deviation. (d) Wheel mounting distance deviation.
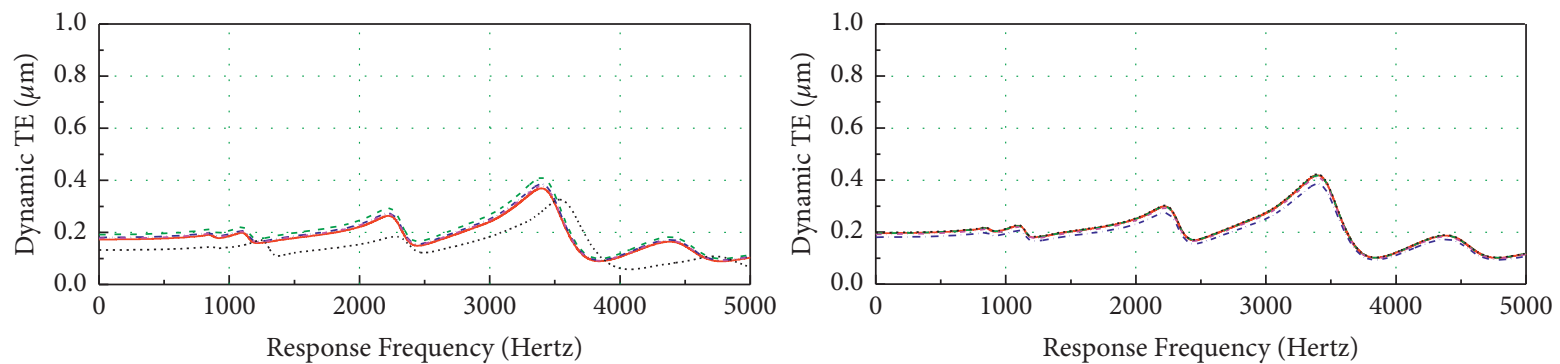

- $\Delta \Sigma=0.3 \mathrm{mrad}$, max value $=0.37$

- - $\Delta \Sigma=0.15 \mathrm{mrad}$, max value $=0.41$

. - - $\Delta \Sigma=0$, max value $=0.38$

-... $\Delta \Sigma=-0.15 \mathrm{mrad}$, max value $=0.38$

… $\Delta \Sigma=-0.3 \mathrm{mrad}$, max value $=0.32$

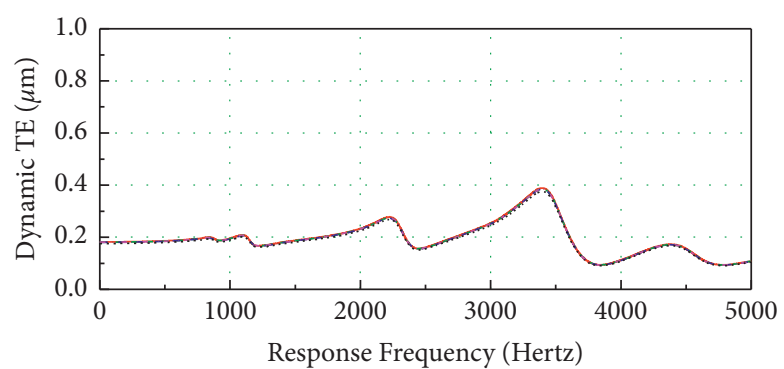

$\Delta \mathrm{E}=0.3 \mathrm{~mm}$, max value $=0.42$

- $-\Delta \mathrm{E}=0.15 \mathrm{~mm}$, max value $=0.42$

. - . $\Delta \mathrm{E}=0$, max value $=0.38$

- ․ $\Delta \mathrm{E}=-0.15 \mathrm{~mm}$, max value $=0.41$

… $\Delta \mathrm{E}=-0.3 \mathrm{~mm}$, max value $=0.42$

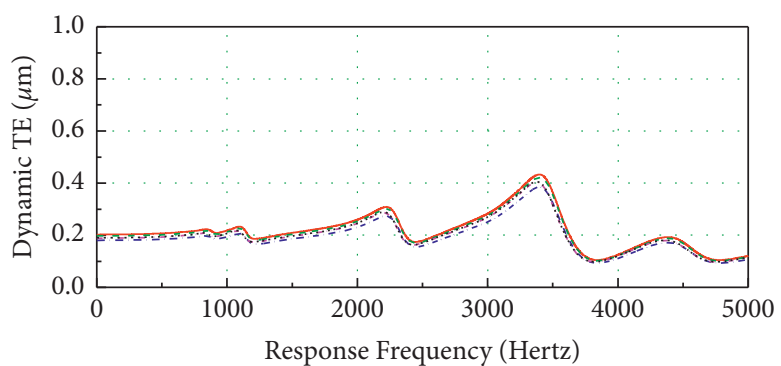

- $\Delta \mathrm{Xp}=0.2 \mathrm{~mm}$, max value $=0.39$

- - - $\Delta \mathrm{Xp}=0.1 \mathrm{~mm}$, max value $=0.38$

- - $\Delta \mathrm{Xp}=0$, $\max$ value $=0.38$

- ‥ $\Delta \mathrm{Xp}=-0.1 \mathrm{~mm}$, max value $=0.38$

… $\Delta \mathrm{Xp}=-0.2 \mathrm{~mm}$, max value $=0.37$

$\Delta \mathrm{Xw}=0.2 \mathrm{~mm}$, max value $=0.43$

- - $-\Delta \mathrm{Xw}=0.1 \mathrm{~mm}$, max value $=0.42$

- $\Delta \mathrm{Xw}=0$, max value $=0.38$

- ‥ $\Delta \mathrm{XW}_{\mathrm{w}}=-0.1 \mathrm{~mm}$, max value $=0.40$

… $\Delta \mathrm{Xw}_{\mathrm{w}}=-0.2 \mathrm{~mm}$, max value $=0.41$

Figure 13: Dynamic transmission error in frequency domain. 

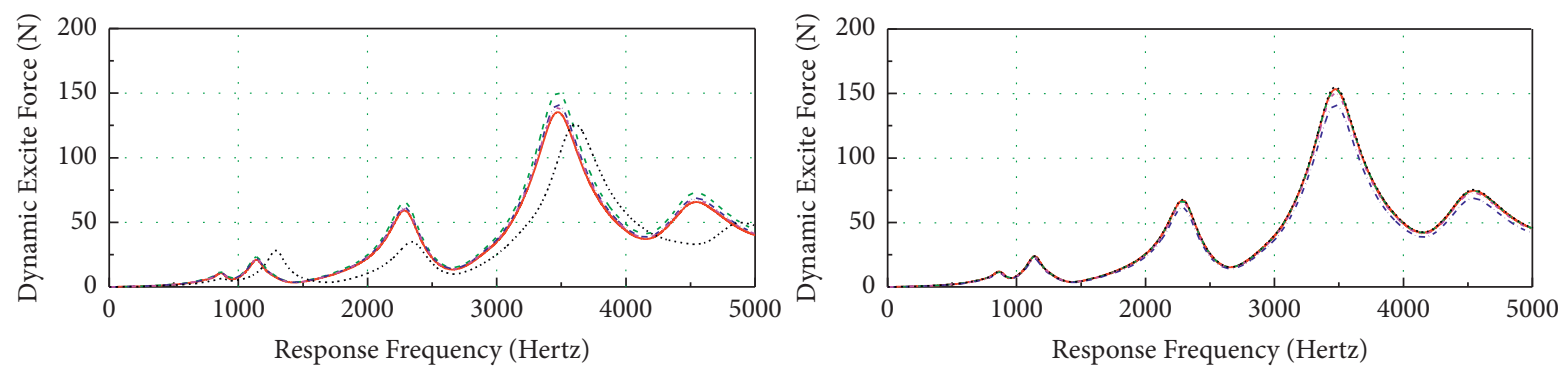

$\Delta \Sigma=0.3 \mathrm{mrad}, \max$ value $=135$

- - $\Delta \sum=0.15 \mathrm{mrad}$, max value $=150$

. - . $\Delta \sum=0$, max value $=141$

- ‥ $\Delta \sum=-0.15 \mathrm{mrad}$, max value $=139$

… $\Delta \sum=-0.3 \mathrm{mrad}, \max$ value $=126$

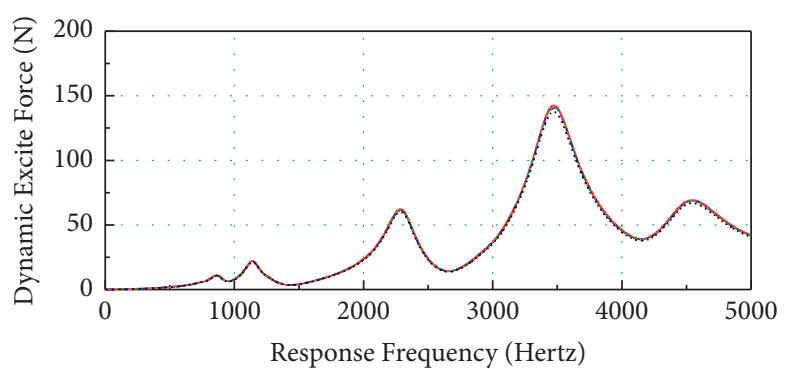

$\Delta \mathrm{E}=0.3 \mathrm{~mm}$, max value $=154$

- - $\Delta \mathrm{E}=0.15 \mathrm{~mm}, \max$ value $=154$

- - - $\Delta \mathrm{E}=0$, max value $=141$

- ․ $\Delta \mathrm{E}=-0.15 \mathrm{~mm}$, $\max$ value $=150$

… $\Delta \mathrm{E}=-0.3 \mathrm{~mm}, \max$ value $=155$

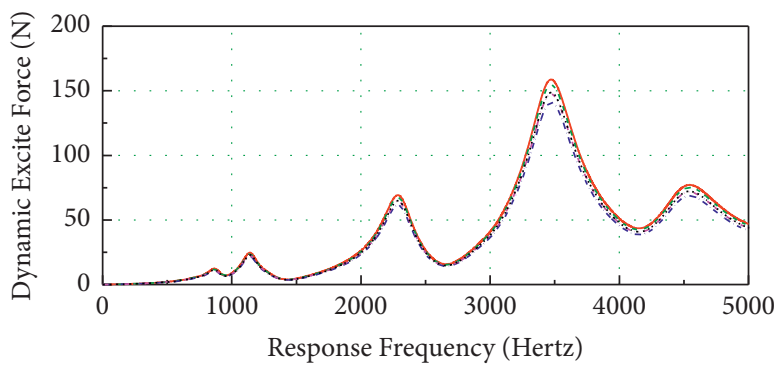

$$
\begin{aligned}
& -\Delta \mathrm{Xp}=0.2 \mathrm{~mm}, \max \text { value }=143 \\
& ---\Delta \mathrm{Xp}=0.1 \mathrm{~mm}, \text { max value }=142 \\
& \cdots-\Delta \mathrm{Xp}=0, \text { max value }=141 \\
& \cdots . \Delta \mathrm{Xp}=-0.1 \mathrm{~mm}, \max \text { value }=142 \\
& \cdots . \Delta \mathrm{Xp}=-0.2 \mathrm{~mm}, \text { max value }=138
\end{aligned}
$$

$$
\begin{aligned}
& \Delta \mathrm{Xw}=0.2 \mathrm{~mm}, \text { max value }=159 \\
& \text { - - } \Delta \mathrm{Xw}=0.1 \mathrm{~mm}, \max \text { value }=155 \\
& \text {. - . } \Delta \mathrm{Xw}=0, \text { max value }=141 \\
& \Delta \mathrm{Xw}=-0.1 \mathrm{~mm}, \text { max value }=148 \\
& \Delta \mathrm{Xw}=-0.2 \mathrm{~mm}, \max \text { value }=149
\end{aligned}
$$

FIgURe 14: Dynamic excite force in frequency domain.

strengthen mesh stiffness and increase peak-to-peak value. The wheel mounting distance deviation $\Delta X_{w}$ has a regular influence on mesh stiffness as same as $\Delta E$, and pinion mounting distance deviation $\Delta X_{p}$ has a great effect on the mesh stiffness.

\subsection{Error Sensitivity Analysis of Gear Dynamic} Characteristics. The misalignment also has a certain influence on the dynamic performance of the gear system, such as dynamic transmission error (DTE) and dynamic excitation force, which are two excitation sources of vibration and noise in the gear system.

4.2.1. Dynamic Transmission Error. The DTE in the frequency domain curves under various misalignments is shown in Figure 13. It can be seen that the negative $\Delta \Sigma$ makes the DTE decline, but the positive $\Delta \Sigma$ changes the DTE indistinctively. The plus or minus $\Delta E$ will increase the DTE value; $\Delta X_{p}$ and $\Delta X_{w}$ have little influence on the DTE. As a result, the negative shaft angle deviation and absolute offset distance deviation have a great effect on the DTE.

4.2.2. Dynamic Excitation Force. The dynamic excitation force (DEF) in the frequency domain curves under diverse misalignment is shown in Figure 14. It can be seen that whether $\Delta \Sigma, \Delta E, \Delta X_{p}$, or $\Delta X_{w}$ has a regular influence on the DEF, the same as DTE above. As a consequence, the negative shaft angle deviation and absolute offset distance deviation have a great effect on the DEF.

4.2.3. Vibration Response Acceleration. The bearing vibration response acceleration (VRA) curves of the support structure response in the frequency domain under diverse misalignment are shown in Figure 15. It can be seen that if $\Delta \Sigma$ is unequal to zero, the VRA of support will decrease; when $\Delta \Sigma=0.3 \mathrm{mrad}$, VRA has reduced about $3.9 \%$, and the frequencies of peak points have not changed, and when $\Delta \Sigma=$ $-0.3 \mathrm{mrad}$, VRA has reduced about $15.5 \%$, but their frequencies of peak points have all increased. Whether $\Delta E$ is positive or negative, VRA will increase about $8 \%$. Otherwise, $\Delta X_{p}$ has a little influence on VRA, and $\Delta X_{w}$ with a range of $-0.2 \mathrm{~mm}$ to $+0.2 \mathrm{~mm}$ can make no more than $12 \%$ increment in VRA.

As a result, the significant influence of misalignment components on the vibration of the transmission system is negative $\Delta \Sigma$, absolute $\Delta E$, and $\Delta X_{w}$; the former tends to improve the dynamic performance, but the latter two are inclined to worsen the dynamic performance. 

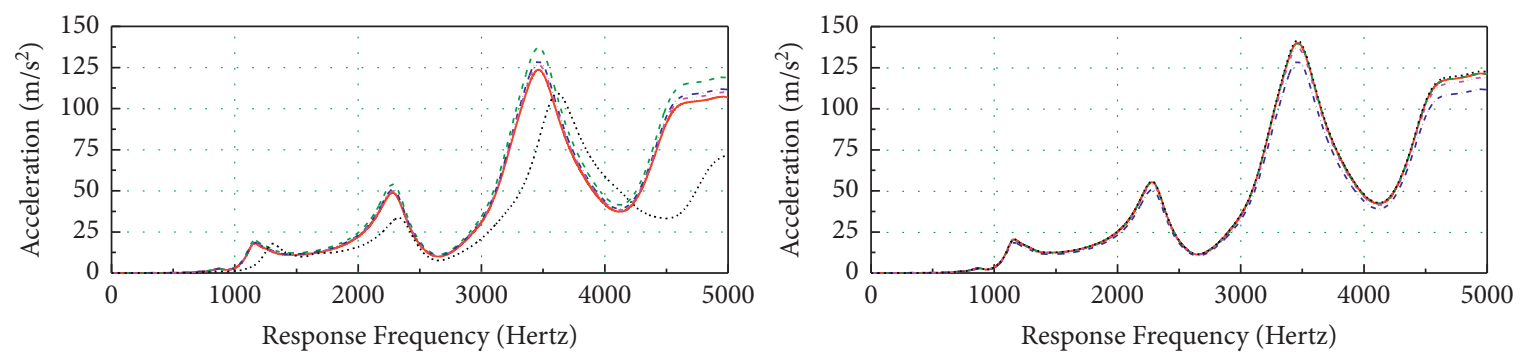
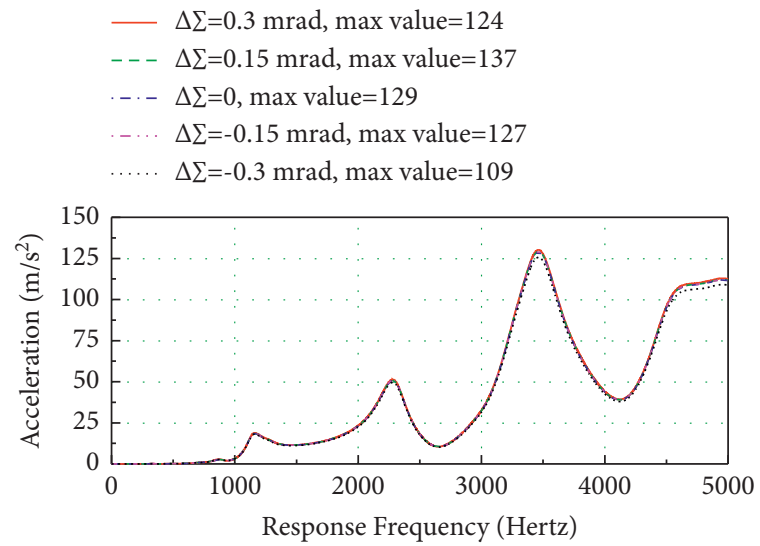

$-\Delta \mathrm{Xp}=0.2 \mathrm{~mm}$, max value $=130$
$---\Delta \mathrm{Xp}=0.1 \mathrm{~mm}$, max value $=130$
$\cdot-\cdot \Delta \mathrm{Xp}=0$, max value $=129$
$-\cdots \Delta \mathrm{Xp}=-0.1 \mathrm{~mm}, \max$ value $=129$
$\cdots \cdots \mathrm{Xp}=-0.2 \mathrm{~mm}, \max$ value $=126$
$\Delta \mathrm{E}=0.3 \mathrm{~mm}$, peak-peak value $=140$

$--\Delta \mathrm{E}=0.15 \mathrm{~mm}$, peak-peak value $=140$

. - . $\Delta \mathrm{E}=0$, peak-peak value $=129$

- ․ $\Delta \mathrm{E}=-0.15 \mathrm{~mm}$, peak-peak value $=137$

… $\Delta \mathrm{E}=-0.3 \mathrm{~mm}$, peak-peak value $=142$

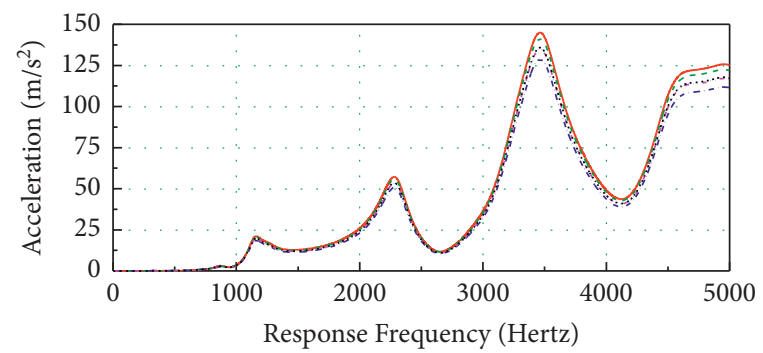

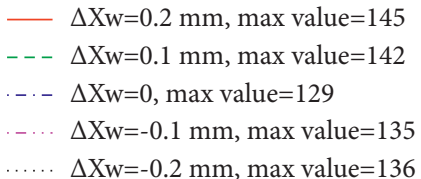

FIgURE 15: Vibration acceleration in frequency domain.

\section{Conclusions and Discussion}

In this paper, an intersecting shaft beveloid gear pair has been taken as the study object. The defects of its theoretical tooth surface in practical application were analyzed. On this base, a modification tooth surface that can improve the gear meshing performance was put forward, and then the sensitivity of the beveloid gear pair under various misalignment errors was analyzed. Finally, the influence law of each component of misalignment errors on the dynamic meshing performance of the gear system has been obtained. Through the above studies, some main conclusions are listed as follows:

(1) The contact pattern of the theoretical tooth surface of the beveloid gear pair is a point, which will expand into line contact after loaded, but the length of the contact line is short, which often leads to large contact stresses and serious edge contact. Therefore, gear modification is recommended, widens the instantaneous contact line length, and eliminates the edge contact to improve the contact stress distribution and fatigue life.

(2) For the intersecting shaft beveloid gear pair, the contact pattern is more sensitive to the shaft angle and offset error but less sensitive to the beveloid gear mounting distance error and almost not sensitive to the helical gear mounting distance error. The contact pattern will move to the toe end if the shaft angle and offset error are positive values and will move to the heel end if they are negative values. TE and PPTE are more sensitive to the offset error and beveloid gear distance error, more sensitive to the negative shaft angle error than the positive value, and almost not sensitive to the helical gear mounting distance error. Except the shaft angle error, the others error will increase the PPTE value. Mesh stiffness is more sensitive to the offset error and beveloid gear mounting distance error; the peak-peak amplitude of mesh stiffness will increase if there exist errors, whether the error is positive or negative. Besides, the shaft angle is not sensitive to meshing stiffness.

(3) The influence of misalignment on the dynamic characteristics of the beveloid gear system is different from the static characteristics. For the dynamic exciting force, the offset error will increase the DEF, but the negative intersection angle error will decrease the DEF. For the vibration response, the offset error will increase VRA, but the shaft angle error will decrease VRA; this is an interesting phenomenon for beveloid gear transmission. In addition, the influence of beveloid gear mounting distance error on the dynamic performance of the gear system is significant. Therefore, the offset and beveloid gear mounting distance deviation have the greatest impact on the system dynamic performance. 
Consequently, in the design process of the gear support structure of beveloid gear transmission, enough stiffness should be designed in the offset direction, and also the assembly error in the offset direction and beveloid gear mounting direction should be as small as possible; these are good for system NVH performance.

\section{Data Availability}

The data cannot be shared due to nondisclosure agreement with the industrial partner.

\section{Conflicts of Interest}

The authors declare that there are no conflicts of interest regarding the publication of this paper.

\section{Acknowledgments}

This research was supported by the National Key Research and Development Project of China (no. TC210H02Q, "Development and Industrialization of High Power and High Efficiency Electric Drivetrain, 2021”).

\section{References}

[1] K. Mitome, "Conical involute gear: part 1. design and production system," Bulletin of JSME, vol. 212, pp. 299-305, 1983.

[2] K. Mitome, "Conical involute gear: part 2. design and production system of involute pinion-type cutter," Bulletin of JSME, vol. 212, pp. 306-312, 1983.

[3] J. Börner, K. Humm, and F. J. Joachim, "“Development of conical involute gears (beveloids) for vehicle transmissions," ASME 2003 International Design Engineering Technical Conferences and Computers and Information In. Engineering Conference, 2003.

[4] H. Komatsubara, K. Mitome, and T. Ohmachi, "Development of concave conical gear used for marine transmissions (1st report, principle of generating helical concave conical gear)," JSME International Journal, Series C Mechanical Systems. Machine Elements and Manufacturing, vol. 451, pp. 543-550, 2002.

[5] H. Komatsubara, K. Mitome, and T. Ohmachi, "Development of concave conical gear used for marine transmissions (2nd report, principal normal radii of concave conical gear and design of a pair of gears)," JSME International Journal, Series C Mechanical Systems, Machine Elements and Manufacturing, vol. 45, pp. 43-550, 2002.

[6] C.-C. Liu and C.-B. Tsay, "Tooth undercutting of beveloid gears," Journal of Mechanical Design, vol. 4, pp. 569-576, 2001.

[7] C. Innocenti, "The kinematics of conical involute gear hobbing," ASME 2007 International Mechanical Engineering Congress and Exposition, vol. 3, pp. 415-424, 2007.

[8] C. Innocenti, "Measurement over balls of conical involute gears," ASME 2009 International Design Engineering Technical Conferences and Computers and Information in Engineering Conference, vol. 6, pp. 3-11, 2009.

[9] C. Brecher, C. Löpenhaus, and J. Brimmers, "Function-oriented tolerancing of tooth flank modifications of beveloid gears," Procedia CIRP, vol. 43, pp. 124-129, 2016.

[10] K. Mitome, "Conical involute gear: part 3. tooth action of a pair of gears," Bulletin of JSME, vol. 245, pp. 2757-2764, 1985.
[11] C. Innocenti, "Analysis of meshing of beveloid gears," Mechanism and Machine Theory, vol. 3, pp. 363-373, 1997.

[12] C. Liu and C. Tsay, "Contact characteristics of beveloid gears," Mechanism and Machine Theory, vol. 37, pp. 333-350, 2002.

[13] C. Liu and C. Tsay, "Mathematical models and contact simulations of concave beveloid gears," Journal of Mechanical Design, vol. 4, pp. 753-760, 2002.

[14] C. Brecher, T. Röthlingshöfer, and C. Gorgels, "Manufacturing simulation of beveloid gears for the use in a general tooth contact analysis software," Production Engineering, vol. 1, pp. 103-109, 2009.

[15] C. Brecher, M. Brumm, F. Hübner et al., "Influence of the manufacturing method on the running behavior of beveloid gears," Production Engineering, vol. 7, pp. 265-274, 2013.

[16] C. Zhu, C. Song, TC. Lim et al., "Geometry design and tooth contact analysis of crossed beveloid gears for marine transmissions," Chinese Journal of Mechanical Engineering, vol. 25, vol. 2, pp. 328-337, 2012.

[17] C. Zhu, H. Wang, M. Liu et al., "Coupled tooth contact analysis of intersected beveloid gears for marine transmissions," International Design Engineering Technical Conferences and Computers and Information in Engineering Conference, ASME, 2013.

[18] C. Zhu, L. Liu, C. Song et al., "Pitch cone design and tooth contact analysis of intersected beveloid gears for marine transmission," Mechanism and Machine Theory, vol. 82, pp. 141-153, 2014.

[19] C. Song, C. Zhu, TC. Lim et al., "Parametric analysis of gear mesh and dynamic response of loaded helical beveloid transmission with small shaft angle," Journal of Mechanical Design, vol. 8, pp. 084501-084508, 2012.

[20] C. Song, C. Zhu, H. Liu et al., "Dynamic analysis and experimental study of a marine gearbox with crossed beveloid gears," Mechanism and Machine Theory, vol. 92, pp. 17-28, 2015.

[21] C. Song, C. Zhu, and W. Liu, "Sliding friction effect on dynamics of crossed beveloid gears with small shaft angle," Journal of Mechanical Science and Technology, vol. 5, pp. 1255-1263, 2013.

[22] T. Do, P. Ziegler, and P. Eberhard, "Simulation of contact forces and contact characteristics during meshing of elastic beveloid gears," Computer Assisted Mechanics and Engineering Sciences, vol. 2, pp. 91-111, 2017.

[23] C. Zhu, C. Song, TC. Lim et al., "Effects of assembly errors on crossed beveloid gear tooth contact and dynamic response," Proceedings of the ASME 2011 International Design Engineering Technical Conferences and Computers and Information in Engineering Conference, vol. 8, pp. 379-387, 2011.

[24] G. Ni, C. Zhu, and C. Song, "Tooth contact analysis of crossed beveloid gear transmission with parabolic modification," Mechanism and Machine Theory, vol. 113, pp. 40-52, 2017.

[25] T. Lin and Z. He, "Analytical method for coupled transmission error of helical gear system with machining errors, assembly errors and tooth modifications," Mechanical Systems and Signal Processing, vol. 91, pp. 167-182, 2017. 